\section{Cognitive requirements of consistent and counterattitudinal roleplaying: A general set effect}

\author{
SCOTT EVENBECK, University of North Carolina, Chapel Hill, N.C. 27514 \\ STEPHEN REISMAN, University of Massachusetts, Amherst, Mass. 02001 \\ and \\ CHESTER A. INSKO*, University of North Carolina, Chapel Hill, N.C. 27514
}

This experiment demonstrates that Greenwald's (1969) finding that the counterattitudinal roleplayer is open-minded can best be described as a general set effect. Potential advocates (counterattitudinal and consistent attitudinal) were found to judge attitudinal statements congruently with their expected roles.

Greenwald (1969) argues that the counterattitudinal roleplayer is open-minded, i.e., that counterattitudinal roleplaying is "... uniquely effective because it succeeds in getting the subject to give impartial evaluation to information opposing his own opinion [p. 387]." $\mathrm{He}$ found that $\mathrm{Ss}$ expecting to argue counterattitudinally for either specialized or general education were significantly more likely to judge as valid statements supporting their assigned roles than were control Ss who had no assigned roles. He also found a nonsignificant tendency for Ss expecting to defend their own positions on specialized or general education to judge as more valid statements supporting their assigned roles than did control Ss who had no assigned roles. Such results possibly indicate a more general set effect rather than a special open-mindedness effect. The nonsignificance of the latter comparison, of course, creates some doubt about the matter. Although Greenwald acknowledges the possible existence of a general set effect, he is inclined to emphasize the special effect of being open-minded.

One methodological problem with Greenwald's experiment is that the control data were collected some time after the experimental data. Since it is the comparison with the control data that allows for the tests that are of major concern here, Greenwald's experiment is by no means definitive. A second problem arises from the comparison of the Ss expecting to defend their own opinions with the control Ss having no advocacy expectation. This is a possible ceiling effect in the validity judgments of the statements concerning specialized and

*Requests for reprints should be sent to Chester A. Insko, Department of Psychology, University of North Carolina, Chapel Hill, N.C. 27514. general education. Since control Ss judge as more valid the statements supporting their own positions, there is a limitation on the amount of further movement in this direction as a function of the set to defend one's own position. Certainly there is less room for movement in the consistent attitude direction than in the counterattitudinal direction. Our solution to this problem is simply to test a somewhat larger number of $\mathrm{Ss}$ than did Greenwald so as to enable a more powerful test of significance. SUBJECTS

The Ss were 219 males and 74 females obtained from the introductory psychology course at the University of North Carolina. There were no differences due to sex, and the data were collapsed over sex. Nine additional Ss did not follow the experimental instructions and were omitted from the analyses.

PROCEDURE

Except for the simultaneous testing of experimental and control Ss, the procedure followed Greenwald's. After reading descriptions of specialized and general education and indicating which they preferred, the experimental Ss were assigned to write essays in favor of either general or specialized education. Control Ss were not assigned an essay-writing role; they were just asked to make validity judgments. The validity judgments for the statements favoring either general or specialized education, obtained from both experimental and control Ss, constituted the main dependent variable. Five evaluative semantic differential scales were also used to obtain a measure of attitude toward general and specialized education. The sum of ratings for general was subtracted from the sum of ratings for specialized.

\section{RESULTS AND DISCUSSION} Validity Judgments

Mean validity judgments in all conditions are presented in Table 1. A least-squares analysis of variance revealed a main effect for initial position $(F=99.95, \quad p<.01$, $\mathrm{df}=1,287$ ), as well as an interaction between advocacy expectation and initial condition $(F=10.25, p<.01$, $\mathrm{df}=2,287$ ). The interaction results from the fact that relative to the expectation of consistent advocacy, the expectation of counter advocacy changed the validity judgments of the Ss initially preferring general education in the specialized direction and the judgments of the Ss initially preferring specialized education in the general direction.

The tests of our hypotheses involve a break down of the above interaction so that each of the advocacy conditions is compared with the control (or no advocacy) condition. To permit independent analyses of variance, the control data were divided randomly so that a sample of controls might be compared with the expectant consistent attitudinal advocators and another sample with the expectant counterattitudinal advocators. Mean validity judgments for consistent advocators are presented in the bottom row of Table 1. In order to test our main hypothesis that a consistent advocacy will produce an advocacy consistent shift in validity judgments, the difference between the general Ss assigned a general advocacy set $(-4.57)$ and specialized Ss assigned a specialized advocacy set (2.96) was compared with the difference between general Ss given no advocacy set $(-3.38)$ and specialized Ss given no advocacy set $(0.63)$. This interaction is significant $(F=6.97, p<.01$, $\mathrm{df}=1,134)$. Thus we have evidence indicating that the set to engage in consistent advocacy does indeed have an effect upon validity judgments. The validity judgments of the consistent attitudinal (expectant) roleplayers are more extreme in the consistent attitudinal direction than are the validity judgments for the controls given no advocacy set.

Greenwald, of course, put major emphasis upon the comparison of the counterattitudinal roleplayers with the controls. The prediction here is that the difference between general Ss assigned specialized $(-2.59)$ and specialized Ss assigned general $(-0.71)$ should be less than the difference between the general $S s$ assigned no advocacy $(-4.23)$ and the specialized Ss assigned no advocacy $(0.74)$. The relevant interaction is significant $(\mathrm{F}=5.66, \mathrm{p}<.02$, df $=1,151)$. Thus there is evidence that the set to advocate counterattitudinally has an effect upon validity judgments.

Attitude Measure

The mean attitude ratings are presented in Table 2. Three of the Ss 
Mean Validity Judgments by Condition of Expected Advocacy and Position

\begin{tabular}{|c|c|c|}
\hline \multirow[b]{2}{*}{ Expectation } & \multicolumn{2}{|c|}{ S's Initial Position } \\
\hline & $\begin{array}{l}\text { Favors } \\
\text { General }\end{array}$ & $\begin{array}{c}\text { Favors } \\
\text { Specialized }\end{array}$ \\
\hline $\begin{array}{l}\text { Counter advocacy expected } \\
\text { No expected advocacy } \\
\text { Consistent advocacy expected }\end{array}$ & $\begin{array}{ll}-2.59 & (59) \\
-3.81 & (85) \\
-4.57 & (54)\end{array}$ & $\begin{array}{rr}-0.71 & (34) \\
0.68 & (38) \\
2.96 & (23)\end{array}$ \\
\hline
\end{tabular}

Note-Cell Ns are given in parentheses. The potential range of the validity measure is from -10 (general education-valid, specialized education-invalid) to +10 (specialized education-valid, general education-invalid).

who made validity judgments did not fill out the attitude ratings and thus are not included in these means. $A$ test of the overall interaction in Table 2 is significant $(F=3.33, p<.05$, df $=2,284$ ), as is the main effect for initial position $(F=285.59, p<.01$, $\mathrm{df}=1,284)$. However, a breakdown of the interaction into its two components (as was done for the validity judgments) did not reveal a significant difference from the control condition for either the consistent advocacy condition or the counter advocacy condition. Such results can be interpreted as simply demonstrating a general set effect.

Table 2

Mean Attitude Ratings by Condition of Expected Advocacy and Position

\begin{tabular}{lcc}
\hline \multirow{1}{*}{ Expectation } & \multicolumn{2}{c}{ S's Initial Position } \\
\cline { 2 - 3 } \multicolumn{1}{c}{ Ex } & $\begin{array}{c}\text { Favors } \\
\text { General }\end{array}$ & $\begin{array}{c}\text { Favors } \\
\text { Specialized }\end{array}$ \\
\hline Counter advocacy expected & $-5.71(58)$ & $5.47(34)$ \\
No expected advocacy & $-6.32(85)$ & $7.05(38)$ \\
Consistent advocacy expected & $-7.56(52)$ & $9.65(23)$ \\
\hline
\end{tabular}

Note-Cell Ns are given in parentheses. The potential range of the attitude rating is from -30 (pro general education, con specialized education) to +30 (pro specialized education, con general education).

The overall results indicate that Greenwald's (1969) emphasis on "open-mindedness" is descriptively inaccurate. Even when Ss expect to defend their own positions and thus demonstrate "closed-mindedness," validity judgments shift congruently. Such results are thus best described as a general set effect. This does not mean, however, that the results are explained by set or that a general set effect is inconsistent with Greenwald's (1970) more recent explanation of open-mindedness in terms of associations being formed between a given attitude position and arguments favorable to that position. Such a general set effect is also not inconsistent with an explanation in terms of the special usefulness of the arguments when presented after role assignment-an explanation that Greenwald (1970) discusses but does not prefer.

\section{REFERENCES}

GREENWALD, A. G. The open-mindedness of the counterattitudinal role player. Journal of Experimental Social Psychology, 1969, 5, 375-388.

GREENWALD, A. G. When does role playing produce attitude change? Toward an answer. Journal of Personality \& Social Psy chology, 1970, 16, 214-219. 